\title{
Cuniculiplasmataceae, their ecogenomic and metabolic patterns, and interactions with 'ARMAN'
}

\author{
Olga V. Golyshina ${ }^{1} \cdot$ Rafael Bargiela $^{1} \cdot$ Peter N. Golyshin ${ }^{1}$
}

Received: 7 September 2018 / Accepted: 20 November 2018 / Published online: 29 November 2018

(c) The Author(s) 2018

\begin{abstract}
Recently, the order Thermoplasmatales was expanded through the cultivation and description of species Cuniculiplasma divulgatum and corresponding family Cuniculiplasmataceae. Initially isolated from acidic streamers, signatures of these archaea were ubiquitously found in various low-pH settings. Eight genomes with various levels of completeness are currently available, all of which exhibit very high sequence identities and genomic conservation. Co-existence of Cuniculiplasmataceae with archaeal Richmond Mine acidophilic nanoorganisms ('ARMAN')-related archaea representing an intriguing group within the "microbial dark matter" suggests their common fundamental environmental strategy and metabolic networking. The specific case of "Candidatus Mancarchaeum acidiphilum" Mia14 phylogenetically affiliated with "Ca. Micrarchaeota" from the superphylum " $\mathrm{Ca}$. Diapherotrites" along with the presence of other representatives of 'DPANN' with significantly reduced genomes points at a high probability of close interactions between the latter and various Thermoplasmatales abundant in situ. This review critically assesses our knowledge on specific functional role and potential of the members of Cuniculiplasmataceae abundant in acidophilic microbiomes through the analysis of distribution, physiological and genomic patterns, and their interactions with 'ARMAN'-related archaea.
\end{abstract}

Keywords Acidophilic archaea $\cdot$ Thermoplasmatales $\cdot$ Cuniculiplasmataceae $\cdot$ Cuniculiplasma $\cdot$ Ca. Micrarchaeota $\cdot$ ARMAN

\section{Introduction}

The history of the order Thermoplasmatales had started in 1970 with the discovery of Thermoplasma acidophilum when Mycoplasma-like cell wall-deficient organism from coal refuse pile was isolated and described (Darland et al. 1970). Noteworthy, in hindsight, this organism appeared to be the first isolated heterotrophic acidophilic archaeon; however, its affiliation with the "Third Domain of Life" was recognised much later. Heterotrophic archaea of the order Thermoplasmatales are broadly distributed geographically

Communicated by S. Albers.

Electronic supplementary material The online version of this article (https://doi.org/10.1007/s00792-018-1071-2) contains supplementary material, which is available to authorized users.

Olga V. Golyshina

o.golyshina@bangor.ac.uk

1 School of Natural Sciences, Bangor University, Deiniol Road, Bangor LL57 2UW, UK and play an important role in carbon cycling in acidic mine drainage (AMD)-impacted and other low-pH natural environments (Golyshina 2011; Justice et al. 2012). Nevertheless, up to now, the iron oxidation ability was confirmed only for Ferroplasmaceae members (Golyshina et al. 2000; Golyshina 2014). Another feature, characteristic of all the studied Thermoplasmatales, with an exception for organisms of the genus Picrophilus, is the lack of cell walls. Currently, the order Thermoplasmatales embraces the most acidophilic organisms described so far and includes six genera with the genus Cuniculiplasma being the most recent member to join the club (Golyshina et al. 2016a). Culture-independent metagenomic studies suggested a significant proportion of archaeal inhabitants of low-pH emplacements affiliated with archaea referred to as "Alphabet plasmas" (Baker and Banfield 2003; Kato et al. 2011; Méndez-García et al. 2014, 2015), whose metabolism and morphology remain unclear and could only be suggested by bioinformatic predictions from metagenomic data. One of these "Alphabet plasmas", designated as "G-plasma", was detected in relatively higher quantities in microbial communities and its genome was 
almost fully assembled (Tyson et al. 2004; Yelton et al. 2013). From the study of isolates of Cuniculiplasma spp. it became apparent that $16 \mathrm{~S}$ rRNA and genome sequences of both strains of Cuniculiplasma divulgatum isolated from sites located $>1000 \mathrm{~km}$ apart exhibited $100 \%$ of $16 \mathrm{~S}$ rRNA gene sequence identity and $>98 \%$ average nucleotide identity (ANI) of genomes with the "G-plasma" metagenomic assembly from Iron Mountain (California, USA) (Tyson et al. 2004; Golyshina et al. 2016a, b), suggesting their affiliation with the same species. Other acidophilic community members detected in a lower abundance in acidic environments represent the so-called 'ARMAN' group (Baker et al. 2006). One of the representatives of this group, namely "Candidatus Mancarchaeum acidiphilum", related to the members of 'ARMAN-2' cluster was shown recently to form an intimate interaction with Cuniculiplasma divulgatum strain PM4 (Golyshina et al. 2017b). The ecophysiological patterns of Cuniculiplasmataceae, geographic distribution, their genomic signatures and their interconnections with 'ARMAN'-like community members are reviewed in this paper.

\section{Biogeography}

Two strains of newly proposed Cuniculiplasma divulgatum were isolated from mine-impacted environments in Europe, namely Cantareras, Spain and Parys Mountain/Mynydd Parys, Wales, UK (Golyshina et al. 2016a).

These organisms were first detected in metagenomic data in microbial biofilms from Richmond Mine AMD system, with $\mathrm{pH}$ about 1 and temperature about $38-42{ }^{\circ} \mathrm{C}$ (Iron Mountain, California, USA) and were dubbed as "G-plasma"; later, the genomic signatures of similar organisms were identified in other acidic sites worldwide (see Tyson et al. 2004 and many others). "G-plasma" (Cuniculiplasmataceae)-related reads were shown to account for up to $22 \%$ of total community proteome in this environment (Richmond Mine, California, USA).

In Frasassi Cave system (Italy) characterised by constant temperatures and $\mathrm{pH}\left(13{ }^{\circ} \mathrm{C}\right.$ and $\left.\mathrm{pH} 0-1\right)$, "G-plasma"related archaea contributed approximately $15 \%$ of total metagenomic reads (Jones et al. 2012). The study recovered that this particular single phylotype constituted 26 of 28 clonal sequences (Jones et al. 2012). Jones et al. (2012) noticed that 1392r, 1492r and A21f primers showed some mismatches with sequences of this group of archaea; however, it contradicts with our results on successfully amplified 16S rRNA sequences of Cuniculiplasmataceae with A21f/1492r primers from environmental samples (Golyshina et al. 2016a, b). Moreover, our census of sequencing data emphasised the presence of these family members in further habitats, such as geothermal areas, cave systems and sulphide ore deposits across continents (Fig. 1, Table S1). For instance, Cuniculiplasma-related organisms inhabited a mat sampled from acidic $\left(28{ }^{\circ} \mathrm{C}\right.$ and $\left.\mathrm{pH} 2.5\right)$ spring field in Owakudani, Hakone, Japan (Kato et al. 2011). Another example is represented by chalcedonic sinters sampled from Yellowstone's Norris Geyser Basin heated by geothermal activity to $35^{\circ} \mathrm{C}$ with pH 1 (Walker et al. 2005). The two latter examples of geothermal habitats suggest that $\mathrm{Cunicu}$ liplasma-related organisms do rather favour moderate-temperature niches. On the other hand, Cuniculiplasma-related signatures were also discovered in metagenomes from hot spring mat sampled in Los Azufres National Park of Mexico, with measured temperature of $73.4{ }^{\circ} \mathrm{C}$ and $\mathrm{pH}$ of 3.8 (Chen et al. 2018).

A closer look at the scattering patterns of Cuniculiplasma spp. in AMD systems revealed their preferences for biofilms and, to a lesser extent, for sediments and surface water samples (Fig. 1).

Both Cuniculiplasma strains were isolated from streamers (green-coloured filaments) formed by microalgae associated with AMD systems from Cantareras, Iberian Pyrite Belt, Spain, and Parys Mountain, UK, which run through copper sulphidic deposits (Golyshina et al. 2016a). During warmer seasons, water surfaces and acid streamers' microniches may warm up to higher temperatures, compared to sediments. The overall temperature regime in such environments is suitable for mesophilic, potentially thermotolerant microorganisms; however, some appearance of thermophilic counterparts cannot be excluded, either. On the other hand, seasonal low temperatures in both AMD environments point at some degree of psychrotolerance, which was, in fact, confirmed by the temperature growth profiles established for both Cuniculiplasma divulgatum strains (Golyshina et al. 2016a). Furthermore, C. divulgatum-related signatures were detected by Ziegler et al. (2013) in samples of snottite biofilms collected from the abandoned pyrite mine in the Harz Mountains in Germany. Localisation of archaea in this ecological niche was perceived to be connected exclusively to anoxic areas, and a common fundamental strategy was suggested for those organisms to rely on metabolic intermediates and end products leaked by other organisms inhabiting the same environment (Ziegler et al. 2013). These points are definitely valid for $C$. divulgatum, which is as experimentally revealed, facultatively anaerobic and heterotrophic organism relying on an external input of organic compounds that it is unable to synthesise (Golyshina et al. 2016a). Furthermore, Krause et al. (2017) produced a stable enrichment culture after 2.5 years of cultivation from that particular sample consisting of four counterparts, including $C$. divulgatum-related organism, as revealed by metagenomic, metatranscriptomic analysis and catalysed reporter deposition fluorescence in situ hybridization (CARD-FISH) visualisation. 


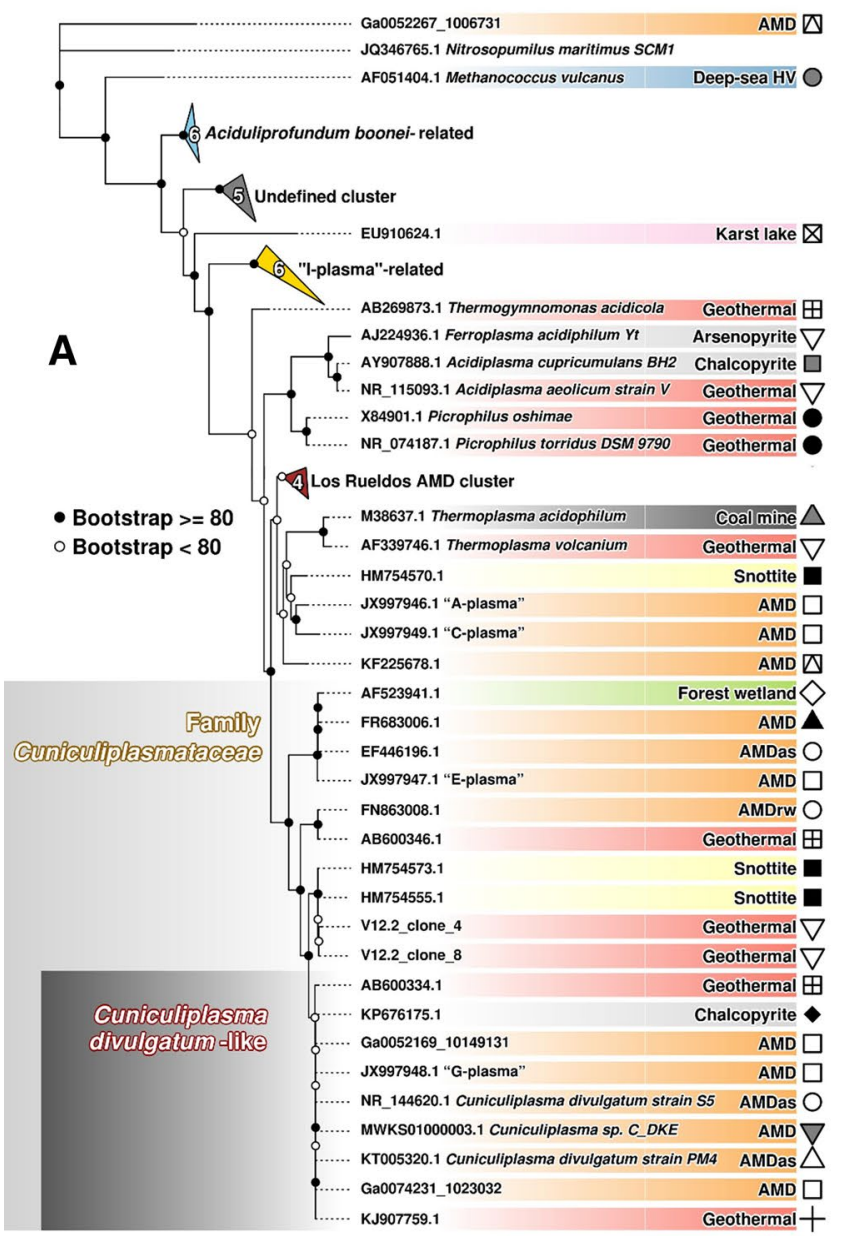

Fig. 1 Phylogenetic and geographical distribution of Thermoplasmatales. 56 rDNA sequences have been used to develop a maximum likelihood phylogenetic tree based on GTR $+\mathrm{I}+\mathrm{G}$ model, represented in $\mathbf{a}$ and c. a The tree showing accession numbers, an affiliation (where it is possible) and environment type (in different colour background). b The geographical location of the isolation sites for the 56 rDNA sequences. Symbols representing each location are also shown

Cuniculiplasmataceae were furthermore detected in sampling spots with lowest dissolved oxygen concentrations of Los Rueldos AMD system described as a stagnant streamer-like microbial mat characterised by $\mathrm{pH}$ about 2 and temperatures ranging between 10 and $17{ }^{\circ} \mathrm{C}$. Redox potential and conductivities within this system were determined as $\sim 256 \mathrm{mV}$ and $5.14-6.72 \mathrm{mS} \mathrm{cm} \mathrm{cm}^{-1}$, respectively, found to be amongst the lowest values for AMD (Méndez-García et al. 2014). In addition, Cuniculiplasma spp. along with Ferroplasma spp. were found in 16S rRNA PCR amplicon reads from enrichment cultures established with Los Rueldos acid streamer samples (Golyshina et al., unpublished).

Short fragments of Cuniculiplasma-related sequences in V3-V4 PCR amplicons were recovered from Copper Cliff AMD pond (SRS404029, Ontario, Canada) and from

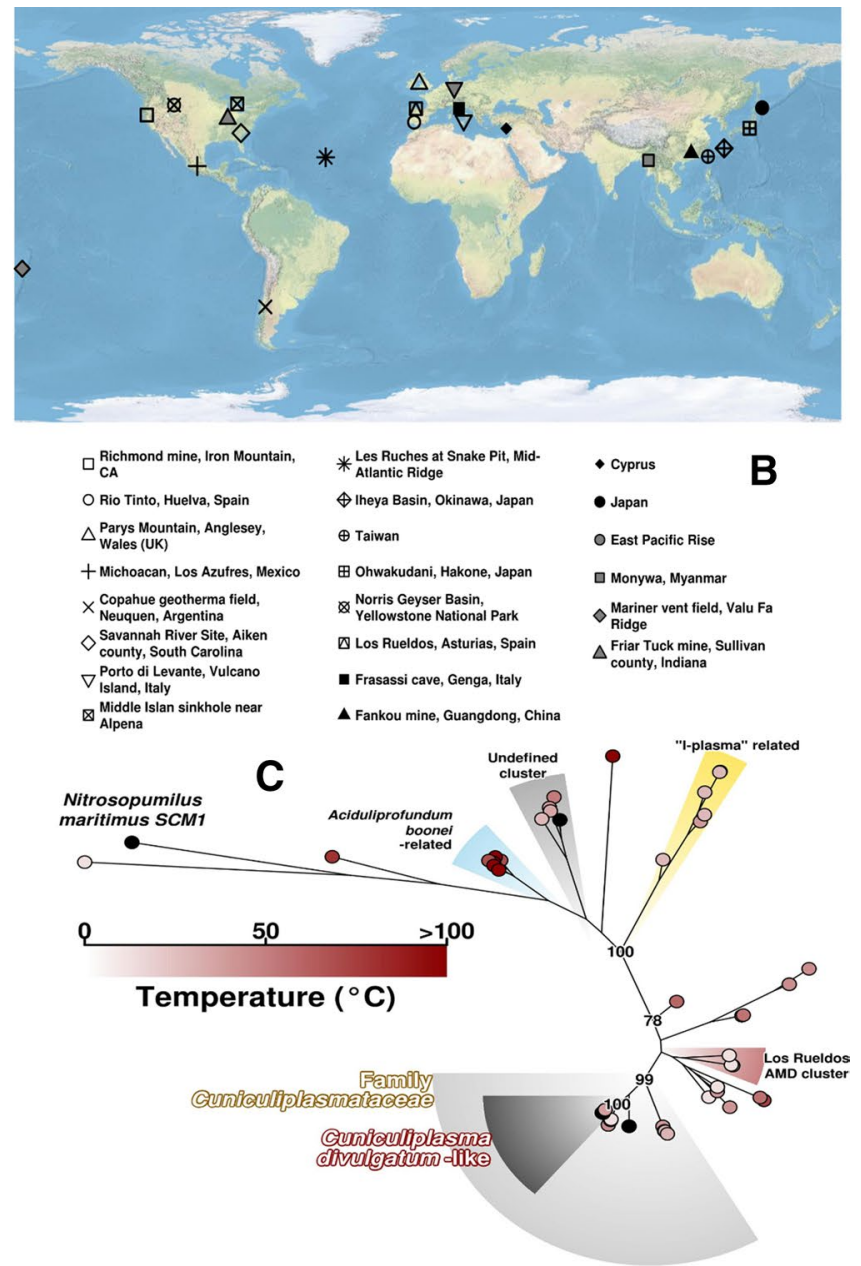

in $\mathbf{a}$, on the right margin. Temperature range in the moment of isolation is represented in $\mathbf{c}$ for each sequence of the tree. All figures have been developed under $\mathrm{R}$ programing environment using the basic $\mathrm{R}$ and the packages OpenStreetMaps, ape and phytools. Deep-sea HV deep-sea hydrothermal vent, $A M D$ acid mine drainage, AMDas AMD acidic stream, AMDrw AMD river water

Southwest China, Guiyang, in sites affected by AMD: soil (SRX1438201) and watershed (SRX655594). Furthermore, in metagenomes from three mining sites in Guangdong province (China) characterised by $\mathrm{pH} 0.83-2.74$, Cuniculiplasma-related archaea (SRX079112, SRX079111 and SRX079110) were found (Chen et al. 2018).

In summary, the archaea of the family Cuniculiplasmataceae are ubiquitously present in natural or man-made ecosystems with low and extremely low $\mathrm{pH}$ and are previously neglected acidophilic cosmopolites (Golyshina et al. 2016b).

The analysis of Cuniculiplasmataceae-derived sequencing data identified their rather wide distribution in relation with habitat temperatures, with a preference to mesophilic growth conditions (Fig. 1). The origins of the data are mostly limited to the northern hemisphere, and it seems 
feasible that the further species and genera do exist within this family. Thus, based on the phylogeny of 16S rRNA gene sequences we suggest the existence of another, in addition to $C$. divulgatum, species within the genus Cuniculiplasma and probably another genus within the family Cuniculiplasmataceae (Fig. 1). Since the 16S rRNA gene sequence identity level above $90 \%$ cut-off suggests organisms belong to the same family, we consider the numerous uncultured organisms clustering together with $C$. divulgatum strains above that threshold form the family Cuniculiplasmataceae. "G-plasma" cluster is, therefore, equivalent to a validly published taxon, the family Cuniculiplasmataceae, and the original 'G-plasma' metagenomic assembly (Tyson et al., 2004) was derived from the organism of the species $C$. divulgatum, sharing $>97 \%$ of average nucleotide identity (ANI) with the type strain $C$. divulgatum S5.

\section{Genomic diversity and conservation}

Currently, altogether eight genomes of Cuniciliplasmarelated organisms from Eurasia, South and North America are available. The first metagenomic assembly of 'G-plasma' was done by Tyson et al. (2004) and furthermore analysed by Yelton et al. (2013). The only complete (ungapped) genomes from this group of organisms were produced for strains S5 and PM4 of $C$. divulgatum by Golyshina et al. (2016b). The genome of C_DKE variant (100\% identity with 16S rRNA genes with both $C$. divulgatum strains) was recovered from the enrichment culture (Krause et al. 2017). All the above genomes exhibited extremely high similarities despite various degrees of their completeness (Chen et al. 2018). Additionally, genomes of Cuniculiplasma-related species were retrieved from metagenomes from AMD (Fankou, China), from two geothermal areas located in Tengchong, China, and in Los Azufres National Park (Mexico) and from an enrichment culture established with samples from Yunfu Pyrite Mine (China) (Chen et al. 2018). Comparison of genomes of $C$. divulgatum strains S5 and PM4 and of 'G-plasma' showed average nucleotide identity (ANI) between both isolates S5 and PM4 at 98.8\%. 'G-plasma' genome showed ANI values of $98.7 \%$ with S5 and $98.4 \%$ with PM4 strains suggesting affiliation of all organisms to the same species, considering the generally accepted ANI threshold for same species being $>95 \%$. High levels of average amino acid identity (AAI) were identified as well, $98.84 \%$ between both strains and $98.37 \%$ and $98.4 \%$ between "G-plasma" variant and strains S5 and PM4, respectively. Moreover, 1174 protein groups comprised the core in silico proteome of $C$. divulgatum strains and 'G-plasma' (Golyshina et al. 2016a, b).
Comparison of $C$. divulgatum genome with C_DKE variant from enrichment culture, established from a snottite sample from Harz Mountains, Germany, has been reported by Krause et al. (2017). Altogether, 1426 gene families were found to be present in both the indicated genomes; however, 80 and 445 families were revealed to be unique for C. divulgatum S5 and to C_DKE metagenomic assembly (the completeness of the latter estimated as $86 \%$ ), correspondingly. In this work, the enrichment culture from Harz Mountains sample was grown under anaerobic conditions at lower temperature $\left(22{ }^{\circ} \mathrm{C}\right)$, which probably explains its slower growth in laboratory (Krause et al. 2017), as compared with the strains S5 and PM4, whose mesophilic and facultatively anaerobic and heterotrophic lifestyles have been shown through cultivation experiments (Golyshina et al. 2016a). Cuniculiplasmataceae archaea, like all extreme acidophiles, flourish in ecosystems characterised by acidic $\mathrm{pH}$, high concentrations of metals or metalloids. As heterotrophs, Cuniculiplasmataceae rely on organic compounds as carbon and energy sources. The origin of organic carbon in their natural habitats could be from dead cells, a from exudates from metabolising cells, or from primary producers, such as acidophilic algae; indeed, both Cuniculiplasma strains were isolated from environments containing high proportion of algae, whose metabolites could be substantial to support the life of these archaea.

Up to now, Cuniculiplasma divulgatum, together with archaea of the family Ferroplasmaceae, are the only cultivated archaeal representatives from moderate- and low-temperature acidic sites. Iron oxidation, which is considered as a highly possible metabolic feature for inhabitants of ferrous and ferric-rich environments, was not confirmed for Cuniculiplasma divulgatum strains; this trait is still exclusively found in archaea of the family Ferroplasmaceae (Golyshina 2014; Golyshina et al. 2017a). Regarding the iron oxidation, some points need to be emphasised here. Genes encoding homologs of rusticyanin or sulfocyanin are often associated with GI (Genomic Islands) in Thermoplasmatales, as shown for Picrophilus torridus, Ferroplasma acidiphilum and Cuniculiplasma divulgatum and could be transmitted via the lateral gene transfer (Fütterer et al. 2004; Golyshina et al. 2017a, and also please see below). More importantly, the presence of these genes in genomes is not necessarily an indication of iron oxidation capacity, as show the examples of some Sulfolobus spp., Picrophilus torridus or Cuniculiplasma divulgatum (Fütterer et al. 2004; Golyshina et al. 2016a, b).

The genomic analysis revealed particular compelling genomic features found for these organisms (Golyshina et al. 2016b). Cuniculiplasma species were considered to possess an ancestral form of A-type terminal oxygen reductase/A1-type heme-copper oxidases forming a distinct clade, located near the B-type oxygen reductases 
and the root of all the other A-type reductases (Golyshina et al. 2016b). The analysis of central metabolic processes of Cuniculiplasma spp. delineated key mechanisms and fundamental principles for archaea of the order Thermoplasmatales (Golyshina et al. 2016b; Krause et al. 2017). There was an absence in both genomes of entire pathways for biosynthesis of several amino acids and the presence of peptidases, peptide/amino acids transporters (Golyshina et al. 2016b). This modulates and controls the important mode of action and impact on the microbiota influenced by dependence on external sources of these biomolecules and, therefore, determines the specific role of these archaea as scavengers of complex organic compounds provided by their microbial neighbourhood. Interesting is also the remarkable conservation within GI for these three genomes derived likely from other euryarchaea populating the very same environments. This persistent flow of particular genetic pool's counterparts appears as an important part of adaptive strategy of these organisms. The GIs bear genes for toxin-antitoxin, restriction-modification systems and metal-, efflux-, transport-, and oxidative stress response-related proteins (Golyshina et al. 2016b). These 'defence' islands facilitate a prompt resilience and adaptation of these archaea to the potential viral attack and high concentration of metals. Furthermore, Cuniculiplasma genomes encode the clustered regularly interspaced short palindromic repeats (CRISPR)-Cas defence systems. About 9\% of all palindromic repeats in the genome C. divulgatum PM4 and 7\% of those in strain S5 showed 90-100\% sequence identity with microbial and viral sequences in Richmond Mine, pointing at the existence of common viruses in all three acidic ecosystems (Golyshina et al. 2016b). Nevertheless, up to now no archaeal viruses were isolated from mesophilic acidic environments (Krupovic et al. 2018). Two types of viruses of spindle and rod shape associated with some small cells considered to be 'ARMAN' related have been recognised by electron microscopy from Iron Mountain AMD site (California, USA), though no information on taxonomic affiliation of those was presented (Comolli et al. 2009). Metagenomic survey of Andersson and Banfield (2008) suggested the presence of proviruses in the virosphere in the above site. For some viral types, connectivity was predicted for rather immense host range among Thermoplasmatales-related archaea represented by metagenomic variants, and for some viruses to be linked to singular community members only (Andersson and Banfield 2008). A further research into the viruses specific to the mesophilic acidophilic archaea requires more attention to shed some light on these, currently neglected, drivers shaping the composition of acidophilic microbial communities.

\section{Interconnection of Cuniculiplasmas with 'ARMAN' archaea}

In the process of isolation of Cuniculiplasma divulgatum strain PM4, its co-culturing 'ARMAN'-2-like organism, "Candidatus Mancarchaeum acidiphilum" Mia14 was reported (Golyshina et al. 2017b). "Ca. Mancarchaeum acidiphilum" belongs to 'ARMAN' cluster. The presence of these deeply branching lineages in acidic samples from Iron Mountain (CA, USA) together with numerous uncultured Thermoplasmatales archaea was discovered by shotgun sequencing (Baker et al. 2006, 2010). Represented in minor quantities in environmental settings, these filterable archaea belong to the "microbial dark matter" and lack functional characterisation. "Candidate Micrarchaeota" and " $\mathrm{Ca}$. Parvarchaeota" reflecting 'ARMAN" diversity were proposed and both candidate phyla were later included into the 'DPANN' 'superphylum' (Rinke et al. 2013). However, it remained unclear which archaea of the order Thermoplasmatales could serve as hosts for 'ARMAN' and what is the level of interdependency between these organisms.

The analysis of the co-culture of $C$. divulgatum, strain PM4 with " $\mathrm{Ca}$. Mancarchaeum acidiphilum" (ca. 10\% genomic reads or $20 \%$ or the total population) revealed that the ungapped genome of Mia14 (the only completed genome of 'ARMAN'-related organism up to now) lacked main metabolic pathways, pointing at reliance on host metabolites. TCA cycle, glycolysis, and other central pathways were either absent or incomplete in the genomic blueprint of Mia14 (Golyshina et al. 2017b). Furthermore, many metabolic precursors (amino acids, cofactors, nucleotides and others) were not found to be encoded by the genome. A puzzling issue is related to the ability of independent respiration in Mia14; while all genes coding for cytochrome $b d$ quinol oxidase were identified, its genome is completely devoid in any genetic loci for the synthesis of isoprenoid quinones, the only electron donors for this enzyme complex. In this regard, the utilisation by Mia14 of Cuniculiplasma membrane quinones originated from living or dead cells has been proposed as the only feasible explanation (Golyshina et al. 2017b). The reduced genome size $(0.95 \mathrm{Mbp})$ together with limited metabolic capability considered its "ectoparasitic" lifestyle and dependence on C. divulgatum PM4. Derived from the genome analysis, cultivation settings and fluorescence microscopy data, the conclusion was made that the external supplement of proteinaceous substrates and amino acids may also be essential for the growth of Mia14. CARD-FISH data suggested that cells of Mia14 were of a greater sizes than generally predicted for 'ARMAN', significantly exceeding the diameter of membrane filter pores $(0.22 \mu \mathrm{m})$, the 
same observation was done early for other organisms of the order Thermoplasmatales (Golyshina et al. 2017b). Comparative genomic analysis of Cuniculiplasma isolates PM4 and S5 and shotgun sequence data of samples from Parys Mountain indicated significant genes' flow in situ between Mia14 and its putative host. Among organisms of 'DPANN' 'superphylum', Mia14 experienced the biggest gene loss while evolving from its closest ancestor.

It is worth noting the presence in the genome of Mia14 of two recognisable type IV pili systems and a number of genes encoding glycoprotein (laminin-like), linked to the formation of extracellular matrix, important in cell-to-cell interactions. Some of these laminin-coding genes are located in a close proximity to type IV pili genes and within a GI. Altogether, the genome analysis and laboratory experiments suggested Cuniculiplasma spp. as an essential host to support the lifestyle of Mia14 archaeon, whereby diverse systems, such as membrane channels, surface proteins and pili may facilitate the exchange of macromolecules and their precursors, and DNA transfer between these two organisms (Golyshina et al. 2017b).

In a similar independent study, the enrichment culture established with snottite sample from Harz Mountains was shown to harbour four organisms, including one related to 'ARMAN'-1. Besides this organism, the consortium consisted of two Thermoplasmatales (one of which was a B_DKE related to Thermogymnomonas acidicola and Cuniculiplasma divulgatum, with the SSU rRNA gene sequence identity of $91.6 \%$, and $91.7 \%$, correspondingly, and another, C_DKE, presented in minor quantities only, with $100 \%$ SSU rRNA gene sequence identity to $C$. divulgatum) and a fungus. CARDFISH data suggested associations of 'ARMAN' cells with both Thermoplasmatales (Krause et al. 2017).

Chen et al. (2018) discussed the metabolic potential of 'ARMAN' archaea, their biogeographical patterns and evolutionary history. Authors suggested 'ARMAN' have some deficiencies in biosynthetic pathways for amino acids and nucleotides, similar evolutionary patterns of energy-generating metabolic pathways, and potential dependency of Thermoplasmatales in situ. At the same time, the study suggested very versatile catabolic abilities in 'ARMAN' towards various organic substrates, which are more typical for free-living organisms and somewhat contradict the hypothesis of ectoparasitism and strict dependency on the host. The wide distribution of 'ARMAN'-related signatures in diverse environments advocates that these archaea might live in close proximity to numerous distinct Thermoplasmatales organisms (Chen et al. 2018).

\section{Conclusion}

The high relative abundance of Cuniculiplasmataceae in hyperacidic environments and their global ubiquity point at their functional importance and substantial contribution to the processes of element cycling in these habitats, though cultured isolates are still merely represented in the family. The first insights into their metabolism and lifestyles were gained thanks to the successful isolation of the two strains and their consequent experimental physiological studies supported by the analyses of the first two high-quality, ungapped genomes representing this family. A high level of conservation of genomes in geographically distant habitats, similar adaptive strategies to cope with environmental conditions, acquisition of 'defence' genomic islands for antiviral or to high metal concentrations resistance contribute to their success in colonisation of a variety of acidic environments. Their co-existence with 'ARMAN'-related organisms shown in the laboratory culture and in natural habitat has unambiguously established the full dependency of the latter 'DPANN' representatives on particular Cuniculiplasmataceae in acidophilic microbiomes. Serving as a host, Cuniculiplasmataceae provide key metabolites for growth and energy generation to " $\mathrm{Ca}$. Micrarchaeota" and promote environmental survival of these elusive organisms. The success in cultivation of pure and binary cultures will further advance our understanding of interactions and specific roles of acidophilic archaea in extremely low $\mathrm{pH}$ environments.

Acknowledgements We acknowledge the support of the Centre of Environmental Biotechnology Project co-funded by the European Regional Development Fund (ERDF) through the Welsh Government. R.B. and P.N.G. acknowledge the support of the Supercomputing Wales project, which is part-funded by the European Regional Development Fund (ERDF) via the Welsh Government.

Funding The work of O.V.G. and P.N.G. was supported by the Royal Society UK-Russia Exchange Grant \#IE 160224, ERA Net IB2 Project MetaCat through UK Biotechnology and Biological Sciences Research Council (BBSRC) Grant BB/M029085/1.

\section{Compliance with ethical standards}

Conflict of interest The authors declare no conflicts of interest.

Open Access This article is distributed under the terms of the Creative Commons Attribution 4.0 International License (http://creativeco mmons.org/licenses/by/4.0/), which permits unrestricted use, distribution, and reproduction in any medium, provided you give appropriate credit to the original author(s) and the source, provide a link to the Creative Commons license, and indicate if changes were made.

\section{References}

Andersson AF, Banfield JF (2008) Virus population dynamics and acquired virus resistance in natural microbial communities. Science 320(5879): 1047-1050

Baker BJ, Banfield JF (2003) Microbial communities in acid mine drainage. FEMS Microbiol Ecol 44:139-152 
Baker BJ, Tyson GW, Webb RI, Flanagan J, Hugenholtz P, Allen EE, Banfield JF (2006) Lineages of acidophilic archaea revealed by community genomic analysis. Science 314(5807):1933-1935

Baker BJ, Comolli LR, Dick GJ, Hauser LJ, Hyatt D, Dill BD, Land ML, Verberkmoes NC, Hettich RL, Banfield JF (2010) Enigmatic, ultrasmall, uncultivated archaea. Proc Natl Acad Sci USA 107(19):8806-8811

Chen LX, Méndez-García C, Dombrowski N, Servín-Garcidueñas LE, Eloe-Fadrosh EA, Fang BZ, Luo ZH, Tan S, Zhi XY, Hua ZS, Martinez-Romero E, Woyke T, Huang LN, Sánchez J, Peláez AI, Ferrer M, Baker BJ, Shu WS (2018) Metabolic versatility of small archaea Micrarchaeota and Parvarchaeota. ISME J 12(3):756-775

Comolli LR, Baker BJ, Downing KH, Siegerist CE, Banfield JF (2009) Three-dimensional analysis of the structure and ecology of a novel, ultra-small archaeon. ISME J 3:159-167

Darland G, Brock TD, Samsonoff W, Conti SF (1970) A thermophilic, acidophilic mycoplasma isolated from a coal refuse pile. Science 170(3965):1416-1418

Fütterer O, Angelov A, Liesegang H, Gottschalk G, Schleper C, Schepers B, Dock C, Antranikian G, Liebl W (2004) Genome sequence of Picrophilus torridus and its implications for life around $\mathrm{pH} 0$. Proc Natl Acad Sci USA 101(24):9091-9096

Golyshina OV (2011) Environmental, biogeographic, and biochemical patterns of archaea of the family Ferroplasmaceae. Appl Environ Microbiol 77:5071-5078

Golyshina OV (2014) The family ferroplasmaceae. In: Rosenberg E, DeLong EF, Lory S, Stackebrandt E, Thompson F (eds) The Prokaryotes: other major lineages of bacteria and the archaea. Springer Verlag, Berlin Heidelberg, pp 29-34

Golyshina OV, Pivovarova TA, Karavaiko GI, Kondratéva TF, Moore ER, Abraham WR, Lünsdorf H, Timmis KN, Yakimov MM, Golyshin PN (2000) Ferroplasma acidiphilum gen. nov., sp. nov., an acidophilic, autotrophic, ferrous-iron-oxidizing, cell-wall-lacking, mesophilic member of the Ferroplasmaceae fam. nov., comprising a distinct lineage of the archaea. Int J Syst Evol Microbiol 50(3):997-1006

Golyshina OV, Lünsdorf H, Kublanov IV, Goldenstein NI, Hinrichs KU, Golyshin PN (2016a) The novel, extremely acidophilic, cell wall-deficient archaeon Cuniculiplasma divulgatum gen. nov., sp. nov. represents a new family of Cuniculiplasmataceae fam. nov., order Thermoplasmatales. Int J Syst Evol Microbiol 66:332-340

Golyshina OV, Kublanov IV, Tran H, Korzhenkov AA, Lünsdorf H, Nechitaylo TY, Gavrilov SN, Toshchakov SV, Golyshin PN (2016b) Biology of archaea from a novel family Cuniculiplasmataceae (Thermoplasmata) ubiquitous in hyperacidic environments. Sci Rep 6:39034

Golyshina OV, Tran H, Reva ON, Lemak S, Yakunin AF, Goesmann A, Nechitaylo TY, LaCono V, Smedile F, Slesarev A, Rojo D, Barbas C, Ferrer M, Yakimov MM, Golyshin PN (2017a) Metabolic and evolutionary patterns in the extremely acidophilic archaeon Ferroplasma acidiphilum $\mathrm{Y}(\mathrm{T})$. Sci Rep 7(1):3682

Golyshina OV, Toshchakov SV, Makarova KS, Gavrilov SN, Korzhenkov AA, La Cono V, Arcadi E, Nechitaylo TY, Ferrer M,
Kublanov IV, Wolf YI, Yakimov MM, Golyshin PN (2017b) "ARMAN" archaea depend on association with euryarchaeal host in culture and in situ. Nat Commun 8:60

Jones DS, Albrecht HL, Dawson KS, Schaperdoth I, Freeman KH, Pi Y, Pearson A, Macalady JL (2012) Community genomic analysis of an extremely acidophilic sulfur-oxidizing biofilm. ISME J 6:158-170

Justice NB, Pan C, Mueller R, Spaulding SE, Shah V, Sun CL, Yelton AP, Miller CS, Thomas BC, Shah M, VerBerkmoes N, Hettich R, Banfield JF (2012) Heterotrophic archaea contribute to carbon cycling in low-pH, suboxic biofilm communities. Appl Environ Microbiol 78:8321-8330

Kato S, Itoh T, Yamagishi A (2011) Archaeal diversity in a terrestrial acidic spring field revealed by a novel PCR primer targeting archaeal 16S rRNA genes. FEMS Microbiol Lett 319(1):34-43

Krause S, Bremges A, Münch PC, McHardy AC, Gescher J (2017) Characterisation of a stable laboratory co-culture of acidophilic nanoorganisms. Sci Rep 7(1):3289

Krupovic M, Cvirkaite-Krupovic V, Iranzo J, Prangishvili D, Koonin EV (2018) Viruses of archaea: structural, functional, environmental and evolutionary genomics. Virus Res 244:181-193

Méndez-García C, Mesa V, Sprenger RR, Richter M, Diez MS, Solano J, Bargiela R, Golyshina OV, Manteca Á, Ramos JL, Gallego JR, Llorente I, Martins dos Santos VA, Jensen ON, Peláez AI, Sánchez J, Ferrer M (2014) Microbial stratification in low pH oxic and suboxic macroscopic growths along an acid mine drainage. ISME J 8(6):1259-1274

Méndez-García C, Peláez AI, Mesa V, Sánchez J, Golyshina OV, Ferrer M (2015) Microbial diversity and metabolic networks in acid mine drainage habitats. Front Microbiol 6:475

Rinke C, Schwientek P, Sczyrba A, Ivanova NN, Anderson IJ, Cheng JF, Darling A, Malfatti S, Swan BK, Gies EA, Dodsworth JA, Hedlund BP, Tsiamis G, Sievert SM, Liu WT, Eisen JA, Hallam SJ, Kyrpides NC, Stepanauskas R, Rubin EM, Hugenholtz P, Woyke T (2013) Insights into the phylogeny and coding potential of microbial dark matter. Nature 499:431-437

Tyson GW, Chapman J, Hugenholtz P, Allen EE, Ram RJ, Richardson PM, Solovyev VV, Rubin EM, Rokhsar DS, Banfield JF (2004) Community structure and metabolism through reconstruction of microbial genomes from the environment. Nature 428(6978):37-43

Walker JJ, Spear JR, Pace NR (2005) Geobiology of a microbial endolithic community in the Yellowstone geothermal environment. Nature 434(7036):1011-1014

Yelton AP, Comolli LR, Justice NB, Castelle C, Denef VJ, Thomas BC, Banfield JF (2013) Comparative genomics in acid mine drainage biofilm communities reveals metabolic and structural differentiation of co-occurring archaea. BMC Genom 14:485

Ziegler S, Dolch K, Geiger K, Krause S, Asskamp M, Eusterhues K, Kriews M, Wilhelms-Dick D, Goettlicher J, Majzlan J, Gescher J (2013) Oxygen-dependent niche formation of a pyrite-dependent acidophilic consortium built by archaea and bacteria. ISME J 7(9):1725-1737 